\title{
CRISIS, DECONSTRUCCIÓN Y EMPATÍA: LA SEMIOSIS DEL ESPACIO URBANO EN LA POESÍA ARGENTINA RECIENTE
}

\author{
María Lucía Puppo \\ Universidad Católica Argentina \\ CONICET \\ luciapuppo@fibertel.com.ar
}

\section{RESUMEN/ ABSTRACT}

El objetivo de este trabajo es realizar un análisis comparativo de la semiosis del espacio urbano en cinco poemarios publicados recientemente en la ciudad de Buenos Aires: Aquel corazón descamisado (2002) de Luis Tedesco, El carrito de Eneas (2003) de Daniel Samoilovich, La rebelión del instante (2005) de Diana Bellessi, Solos y solas (2005) de Tamara Kamenszain y Poemas del sin trabajo (2007) de Eduardo Mileo. En todos ellos se textualizan voces, miradas e itinerarios que atraviesan la ciudad contemporánea, apelando a una gran diversidad de imágenes, tópicos y estrategias discursivas. La tríada conceptual crisis-deconstrucciónempatía permitirá leer en conjunto diferentes modalidades en que los textos poéticos traducen y reenvían a las complejidades del imaginario social.

Palabras clave: Buenos Aires, poesía, crisis, deconstrucción, empatía.

This paper aims to compare the semiosis of urban space in five books of poems recently published in the city of Buenos Aires: Aquel corazón descamisado (2002) of Luis Tedesco, El carrito de Eneas (2003) of Daniel Samoilovich, La rebelión del instante (2005) of Diana Bellessi, Solos y solas (2005) of Tamara Kamenszain, and Poemas del sin trabajo (2007) of Eduardo Mileo. All of them present voices, sights and itineraries of the contemporary city by means of a wide range of images, topics and discursive strategies. The conceptual triad crisis-deconstruction-empathy will allow the systematization of different ways in which poetic texts translate and refer to the complexities of the social imaginary.

KEY WORDS: Buenos Aires, poetry, crisis, deconstruction, empathy. 


\section{LA CIUDAD LATINOAMERICANA: (POS) MODERNIDAD Y GENEALOGÍAS LITERARIAS}

Flanear es un arte que solo los parisienses poseen en todos sus detalles. Domingo F. Sarmiento, Viajes por Europa, África y América.

La prosa de Sarmiento canonizó a Buenos Aires, entonces una gran aldea, como foco civilizador frente al caos de la barbarie. De ese modo, el imaginario decimonónico perpetuaba para la ciudad portuaria el estatus de ciudad letrada como lo definiera Ángel Rama (1984), en tanto dispositivo jerárquico planificador y ordenador del espacio físico y simbólico. La modernidad urbana, que Benjamin describió en la París de fin de siglo a partir de los poemas de Baudelaire, no irrumpió en la poesía del Río de la Plata vía Francia, pues como señaló Jorge Monteleone, "a la aparición del espacio urbano en la poesía simbolista francesa no corresponde puntualmente una temática urbana en la poesía del primer modernismo hispanoamericano" ("Baldomero" 81).

En la vereda opuesta del exotismo lujoso de Darío y Lugones, la presencia protagónica de Buenos Aires en la lírica argentina se inició con las poéticas fundantes de Evaristo Carriego y Baldomero Fernández Moreno, nexos insoslayables con la generación vanguardista (Barrera 87). Siguiendo el camino abierto por ambos predecesores, surge el fervoroso criollismo urbano del primer Borges (Sarlo 44) que veía utópicamente en la capital un espacio de fusión de la ciudad y del campo (Lefere 201), así como la ciudad moderna y dinámica de Oliverio Girondo, la urbe gris, cuadrada y "sepulcral" de los últimos libros de Alfonsina Storni (Salomone 334), o bien, la ciudad hostil, atravesada por problemas sociales y gustos populares en los textos de González Tuñón y Yunque.

Es conocido el trayecto de la narrativa que textualiza la capital argentina e incluye representaciones tan paradigmáticas como las descripciones expresionistas de la ciudad moderna en la narrativa de Arlt, la urbe peronista que presenta Adán Buenosayres (1948) de Leopoldo Marechal, la ciudad dual que oscila entre el ideal clásico y el grotesco realista en los cuentos de Mujica Láinez, la síntesis del Borges maduro de una Buenos Aires mundial, abstracta e imaginaria, hasta el territorio de pesadilla que presenta La ciudad ausente (1992) de Ricardo Piglia (Saítta 143, Depetris 145). Sin embargo, no ha sido una cuestión tan transitada por la crítica el estudio de la poesía que, a partir de la segunda mitad del siglo XX, tiene a la ciudad como escenario y motivo. 
A comienzos del siglo XXI, Buenos Aires es una auténtica ciudad global que concentra nuevas tecnologías para el procesamiento inmediato de la información, donde se produce una creciente estandarización de los productos económicos y sociales, al mismo tiempo que una creciente integración transnacional (Savitch 180-181). Pero como tantas otras ciudades de América Latina, la capital argentina es una "ciudad fragmentada", donde esos estándares globales coexisten con grandes zonas locales de pobreza (Prévôt Schapira 27). La megalópolis resulta inabarcable por extensa y polifacética. Ante la imposibilidad de recorrerla y aprehenderla en su totalidad abrumadora y cambiante, los habitantes nos limitamos a experimentar trayectos parcelarios, erráticos, subjetivos. Poseemos por otra parte una ciudad imaginada, trazada en mapas y aprendida en imágenes, relatos y canciones. Como lo demostró García Canclini respecto de la ciudad de México, todos nos movemos entre la ciudad real y la imaginaria, hasta el punto de que representar la urbe inconmensurable es posible únicamente cuando ésta "se desborda y se multiplica en ficciones individuales y colectivas" (García Canclini 109).

El objetivo de este trabajo es realizar un análisis comparativo de la semiosis del espacio urbano en cinco poemarios publicados recientemente en la ciudad de Buenos Aires: Aquel corazón descamisado (2002) de Luis Tedesco, El carrito de Eneas (2003) de Daniel Samoilovich, La rebelión del instante (2005) de Diana Bellessi, Solos y solas (2005) de Tamara Kamenszain, y Poemas del sin trabajo (2007) de Eduardo Mileo. Escritos en los años inmediatamente posteriores a la crisis económica y social que estalló en la Argentina de diciembre de 2001, todos ellos presentan "micrópolis" o "pequeñas ficciones" de Buenos Aires (García Canclini 113), apelando a una gran diversidad de registros, motivos, imágenes, repertorios temáticos y estrategias discursivas.

El corpus a analizar comprende obras escritas por autoras y autores nacidos entre 1941 y 1953, que pertenecen a una generación madura y que cuentan con una sólida trayectoria poética. Esta selección no busca proveer un muestreo representativo de las diferentes expresiones que registran el impacto de la crisis en la poesía argentina reciente, tarea difícil de concretar en un trabajo de este alcance y que, además, correría el riesgo de resultar simplificadora y prematura. Se trata, en cambio, de detectar recurrencias, disparidades y tensiones en la semiosis del espacio porteño que proponen los textos elegidos, donde la caminata por la ciudad en crisis es una coordenada espacial-dinámica que organiza la densidad semántica del discurso poético y, a la vez, traduce y reenvía a las complejidades del imaginario social. 
La metodología comparatista que proponemos combina cuatro perspectivas de análisis: primero, una perspectiva lingüistica que, partiendo de los índices referenciales y toponímicos, estudia la morfología, sintaxis y semántica del espacio ficcional; segundo, la perspectiva temática, que rastrea los tópicos asociados a la representación urbana en el discurso literario; tercero, la perspectiva intertextual y transdiscursiva, que focaliza en las relaciones con otros géneros (concretamente la crónica y el relato de viaje); cuarto, la perspectiva simbólica y mitológica, que permite reconocer imágenes y arquetipos que remiten tanto a la tradición literaria como a la conciencia histórica y la memoria colectiva.

Para abordar el examen de los cinco poemarios que conforman el corpus distinguiremos en principio dos momentos escriturarios que trascienden en el presente de la enunciación de los textos: la crisis de diciembre de 2001 y la pos-crisis de los años subsiguientes. Con la tríada conceptual crisisdeconstrucción-empatía pretendemos dar cuenta de un itinerario que se perfila en los cinco textos, leídos ya como un conjunto o macrotexto. Finalmente, nuestras conclusiones apuntarán a detectar de qué modo, en el momento presente, ciertos procesos semiótico-literarios dominan y delimitan nuestro conocimiento de la ciudad (Spitta 12). Como todo recorrido, el que aquí proponemos asume el riesgo de resultar poco sistemático y caprichoso en su orden, pero entendemos que solo de ese modo disperso y caótico se nos revela la gran ciudad en su caleidoscópico escenario de personajes, mapas, propuestas y signos ${ }^{1}$.

\section{RADIOGRAFÍAS DE LA CRISIS}

La rebelión del instante (2005), de Diana Bellessi, es un volumen surcado por personajes e historias en diferentes espacios, entre ellos, una Buenos Aires entrañable. El poema titulado "Es toda mi fortuna" ofrece una estampa

1 Este trabajo se inscribe en un proyecto de investigación que versa sobre las representaciones poéticas del viaje en la ciudad contemporánea. El objetivo del mismo es abordar el estudio de textos poéticos hispánicos desde una perspectiva interdisciplinaria que complementa el análisis del discurso lírico con determinadas claves de la poética del relato de viajes. Algunas hipótesis de este artículo fueron leídas y discutidas en la ponencia "Entre cartones y desolación: la crisis del espacio urbano en la poesía argentina reciente", presentadas en el XXVIII International Congress of the Latin American Studies Association, Río de Janeiro, 11-14 de junio de 2009. 
porteña centrada en el elogio del barrio. La cascada de los fresnos presta su follaje a los pájaros y la carne se dora en las parrillas, pero esta paz idílica de "la ciudad / más linda del mundo" (Bellessi 64) es interrumpida por "la melodía letal / que amenaza caer" (66). A continuación sigue "Notas del presente", una sección marcada por un fuerte vínculo referencial con el panorama de la crisis: en las calles reinan el hambre y el frío; frente a una fábrica abandonada algunos buscan alimentos en la basura podrida (86). Se produce un encuentro perturbador con una figura fantasmal vestida en harapos, niña o enana mendicante, quien se encuentra sola como "un pedazo... / de maniquí en la calle // del desamparo" (88). Parodiando el gesto de los humanos, sobrevuela el río un ave carroñera, -“¿Carancho o gavilán?” se pregunta la voz poética-, a la busca de "las tripas del Plata" (87).

Las palabras de Muriel Rukeyser que Bellessi traduce -“quién hablará de estos años / sino yo, sino vos" (71)- funcionan como emblema de esta poesía surgida como crónica o fotografía, anclada en un sentido privilegiado de la contemporaneidad (Scarabelli s/p). Si la descripción realista no anula la ambigüedad y el misterio, también hay signos de esperanza en medio de la tristeza generalizada: los compases de la cumbia resisten en el feriado del primero de mayo (80) y un aura revolucionaria acompaña los piquetes en la capital y el resto de la Argentina $(91,93)$. Es así como en los textos de Bellessi se impone una mirada estética y solidaria de la pobreza, atenta a pequeños signos como el abrigo del sol, que arropa en invierno al modo de un "ponchito" (167).

Los poemas de esta autora leen sin ambages los signos de un tiempo difícil: "este duelar es tan nuevo, / como moscas día a día / el trabajo cae y los niños / de hambre en la patria mía" (72). En ellos se expresa una voz colectiva ("ahora somos todos negros") que mira con agrado las distintas movilizaciones sociales que se producen en torno a asambleas, comedores populares, columnas que marchan y piquetes en todo el país (150). Una variante utópica quiere ver una nueva montonera en esa "gente furiosa pero inocente", "como si estuviéramos construyendo algo" (117).

En El carrito de Eneas (2003), Daniel Samoilovich introduce una vista panorámica de la ciudad de Buenos Aires, apenas perceptible entre el aire oscuro y la niebla. Esta visión de la urbe convertida en ruinas, como una nueva Troya, bien podría ser una versión del cataclismo argentino contemplado por el presidente de la Rúa que parte en helicóptero (García Vega $\mathrm{s} / \mathrm{p}$ ). El protagonista del poemario es un cartonero que avanza por la ciudad revolviendo y acopiando basura en su carrito que, siguiendo el 
paralelismo mitológico, remeda el carro que Vulcano le forjó a Eneas. El diseño del libro responde a la estructura del carrito de Eneas-cartonero, que da nombre a los distintos cantos o secciones: el barral derecho corresponde a Plaza Constitución y el izquierdo a Retiro, mientras que la Base es Plaza Miserere. Surge entonces una grilla que tiene por ejes las tres grandes estaciones de tren que conectan la ciudad con el conurbano bonaerense y que, a su vez, remiten a los cuatro puntos cardinales del territorio argentino. Sobre este fondo común de un gigantesco "campamento de desharrapados" (Samoilovich 11), los travesaños del carrito dan ocasión a los respectivos elogios de los materiales reciclables que los cartoneros rescatan de la basura: papel, vidrio y hojalata.

En este poemario, la mitología latina es un recurso que crea distancia, ficcionaliza y, al mismo tiempo, lleva hasta la hipérbole la representación espacial. El sujeto poético le habla a Marforio, una de las estatuas parlantes de Roma, y en su tono pervive "aquel sabor urbano de la antigua sátira horaciana, que describía su mundo social con insidia" (Monteleone, "Cartoneros" s/p). El fenómeno de la crisis se hace extensivo a la ciudad entera, pues, como Eneas y sus compañeros, "todos gitanean" (Samoilovich 16). En Buenos Aires-Troya es leitmotiv lo falsario, como la imitación de buzo Adidas que lleva puesta un cartonero (Samoilovich 14) o las mercancías fraudulentas que se venden en los puestos ilegales de Retiro: "las radios / que te despiertan en la madrugada / con noticias falsas y siniestras, las pilas más vencidas, / ... los paraguas que ... / han de abrirse / sólo una vez" (29), "revistas de crucigramas ya resueltos, / remeras distinguidas con el más triste de los cocodrilos" (30). En la cadena de significantes plagiarios y falaces se suman también esos símiles de dinero que fueron los bonos Lecop y Patacones $(19,25)$, impresos por el Estado en una economía de emergencia.

La serie de poemas que da título a Aquel corazón descamisado (2002), de Luis Tedesco, se organiza en torno a la travesía de un personaje en la City Porteña, la zona del centro de la ciudad donde se concentra la mayor cantidad de entidades bancarias y financieras, en los aciagos días de diciembre de 2001. Atravesando sucesivos estados de temor, ira e impotencia, el sujeto hace las filas para retirar su dinero como "una rata entre mármoles voraces" (Tedesco 153). Luego de acceder al preciado subsuelo donde están las cajas de seguridad, por fin logra volver a la calma secreta de su casa.

Escrito en una segunda persona furibunda, se trata de "un verdadero relato poético" (Raschella s/p) que transcurre en una "ciudad narcotizada, fraudulenta, / ladina, fugitiva, resignada" (Tedesco 151). El sujeto poético se 
dirige a un interlocutor mediocre - ¿tal vez ese mismo sujeto desdoblado?-, el hombre que se ha visto beneficiado en los años neoliberales y que ahora lamenta el cese de sus privilegios con la devaluación de la moneda. La alocución a este personaje se intercala con los párrafos dirigidos a determinados actores de la escena política y social ${ }^{2}$ y con la presencia de otros personajes que representan distintos arquetipos nacionales, como el poeta provinciano Carlos Mastronardi, el gaucho Juan Moreira, Evita, un general antisemita, un político camaleónico y una dama patricia que reza. Junto a las filas de burgueses abarrotados en los bancos pasan de largo "los oscuros", aquellos que "vienen de cirujear, / de la demarcación racista, / de sus camas cubiertas por el agua" (163). Entre la multitud (irónicamente) republicana también deambula "la Desaparición", el ejército de los "muertos no visibles" que dejó el terrorismo de Estado en los años setenta (160). La ciudad resulta escatológica en los dos sentidos de la palabra: es una Buenos Aires de las postrimerías, donde se anuncia el fin de una era, y se trata además de una ciudad inundada de excremento y suciedad, donde se proyecta "tu caca en el fangal bancario", "la mierda tibia / en el pantalón etimológico" $(151,152)$.

\section{MAPAS DE LA POS-CRISIS}

La madrugada porteña ofrece la intemperie de una calle brumosa y sin árboles (Mileo 13) en Poemas del sin trabajo (2007), de Eduardo Mileo. A veces, el calor es insoportable y, con la sola compañía de las moscas, el caminante baja a tomar agua de un bebedero (19). Tras un breve paso por un café para buscar clasificados en el diario (36), no hay un centro en el deambular del desempleado, ni tampoco en el mapa de su ciudad. El espacio emblemático de la Plaza de Mayo apenas ofrece un hormigueo de gente ante la ausencia de un "cuerpo", es decir, de algo o alguien "que organice una acción" (46). Los barrios del Sur ostentan paisajes grises como el puerto o la iglesia de San Cayetano en Liniers, donde el personaje termina por abandonar la fila

2 La profusión de nombres propios ficticios construidos a partir de referentes extratextuales recuerda el modus operandi del roman à clef. A modo de ejemplo reproducimos tres citas que aluden respectivamente a un dirigente sindical ("ubaldo" por Ubaldini, p. 189), un ex Presidente de la República ("síganme, no los voy a defraudar", slogan utilizado por Carlos Menem, p. 185), y un importante grupo empresario ("Pérez Mal Compacto" por Pérez Companc, p. 192). 
de los creyentes (94). El regreso a casa lo obliga a tomar un colectivo para cruzar la frontera e internarse en los suburbios -Morón, "al occidente" (92); allí "ni el olvido llega / de tan lejos / que queda este páramo" (39).

En un tono sensible tampoco falto de ironía, el texto de Mileo retrata el saldo doloroso del estallido de 2001, ese gran después que siguió a la crisis. Se exploran varias caras del sufrimiento citadino: el de los pescadores de la costanera que no logran obtener presa (23), el de los rostros "ajados por el silencio" que esperan el colectivo, la triste sensación de ser el último de la cola (26). El sin trabajo es un nuevo marginal que se equipara con "el sin amor", subidos ambos al tobogán de la dupla "alcohol y tabaco" (85). Anda desencantado, con la cabeza gacha, mientras sueña con distintos oficios que le están vedados. Atrae la atención de una turista que logra fotografiarlo (40) y se pregunta qué trabajo habría que tener para enamorar a la mujer que baja las escaleras de un edificio de categoría (88). La lluvia se confunde con sus lágrimas, formando un río infinito (31), hasta que eventualmente su estado se asemeja al del agua estancada del cordón (33). La ciudad fluvial impone un ritmo vacilante a su caminata: "la lluvia lo despoja / con la lentitud de una ceremonia"; "Sabe / por primera vez en su vida / que ya no tiene apuro" (45). Vencido y solo como un náufrago o un ahogado, el desempleado se reconoce en el fondo del aljibe (69).

La protagonista de Solos y solas (2005), de Tamara Kamenszain, es una mujer que asume la soledad tras una separación y emprende la búsqueda de una nueva experiencia amorosa. Con ese fin participa asiduamente de diversos encuentros para solteros y divorciados, programados por la máquina de los "celestinajes posmodernos" (Foffani 4). Del salón de baile al departamento donde la espera su cama vacía, esta "cenicienta en radiotaxi" (Kamenszain 15) atraviesa una Buenos Aires vertiginosa y nocturna, donde se adivinan los teatros y pizzerías de la calle Corrientes (13). La danza de los cincuentones sudados es un teatro decadente, protagonizado por "bailarines a la rastra muñecos de aserrín" (13). La ciudad aparece como un espacio de enajenamiento, soledad y roces fugaces. No se mencionan monumentos nacionales ni se nombra a los amigos; el anonimato se extiende sobre la ciudad, sus calles, su arquitectura y sus habitantes. La intimidad buscada afanosamente por la voz poética, que sigue el eco de los boleros y el tango, contrasta con la vorágine de velocidad y peligro que la acecha (Puppo, "Ficción" 482).

El discurso de la primera persona que apuesta al tarot sentimental en este poemario parece, a primera vista, ajeno a la crítica social y la denuncia. 
Sin embargo, en Solos y solas están diseminadas varias marcas que delatan el impacto de la crisis, empezando por los versos que inauguran el libro y que presentan a la voz poética: "Soy la okupa de mi propia casa / desde que la propiedad se fue de mí" (11). Experimentándose a sí misma como una desalojada-usurpadora, a sus anónimos compañeros de baile los llama "gente descamisada" (13) y "parias" (19), en tanto que su posible candidato amoroso es un "indocumentado" (25). La calle le resulta un ámbito transitorio e inseguro; confiesa: "para que no me roben salgo corriendo" (46). En este caso, los medios de transporte constituyen la principal imagen que condensa el movimiento autómata y el ritmo vertiginoso. La entrada al subterráneo es un cotidiano descenso a los infiernos ("me voy de boca el subte está oscuro", 17) análogo al viaje que provoca la fuerza succionante de "un inodoro que nos traga lejos" (11).

\section{VIAJEROS EN LA CIUDAD DIFUSA}

El verdadero caminante es el de un solo camino. El otro será un explorador, un turista, uno que hace la digestión.

Baldomero Fernández Moreno, Guía caprichosa de Buenos Aires.

Apelando a un abanico de tonos que van desde la rabia hasta la esperanza -pasando por la tristeza y el desconsuelo-, los cinco poemarios analizados presentan microficciones de Buenos Aires, es decir, versiones parciales y subjetivas del espacio donde la voluntad imaginativa convive con la referencial. En todos los casos el discurso poético cita y absorbe estrategias de otros géneros, ya sea populares, como la música -tango, bolero, cumbia-, el cine y la publicidad, ya sea cultos, como el ensayo, la narración, el teatro o el mito clásico.

Reflexiones sobre la crisis argentina, el hambre mundial, el amor y lo sagrado impregnan el poemario de Diana Bellessi a partir de pequeñas anécdotas cotidianas trenzadas en un imaginario vegetal, animal o urbano. En La rebelión del instante se construye la figura de la poeta a partir de una voluntad confesional que la presenta a sus cincuenta y seis años soñando (Bellessi 96) y sabiéndose "con la mitad de su hermosura" (Bellessi 16). La intromisión de una veta argumentativa y la (aparente) espontaneidad de los poemas "de ocasión", escritos a propósito de los titulares de los diarios en plena crisis, le otorgan a todo el libro un aire de crónica. Este género 
fronterizo, cercano al testimonio y el nuevo periodismo, coloca a la poeta en el rol de "cronista de su época", según la fórmula de Pablo Neruda (1964). Este tipo de encuadre discursivo permite "experimentar una de las formas posibles del realismo en nuestros días" (Bernabé, "La ciudad" s/p), y su auge actual es un fenómeno ligado a la importancia que el documento y la no ficción tienen también en otros terrenos de la literatura y el arte (Cristoff 21).

Los cuatro poemarios restantes establecen un vínculo más estrecho con el discurso narrativo debido a que presentan el recorrido de un personaje central que se desplaza en determinadas áreas de la ciudad: el viaje del centro al barrio residencial en Kamenszain, el deambular por los barrios del sur en Mileo, la pesquisa de las grandes estaciones de ferrocarril en Samoilovich, la caminata por el microcentro en Tedesco. Según la frecuencia de los desplazamientos, encontramos diversos tipos de itinerarios que confluyen en la sintaxis espacial urbana (Alonso Lera 248-249): los cartoneros de Samoilovich presentan itinerarios rutinarios, como lo es el de Aquiles quien "vela / por el fruto de su jornada cenicienta, / las cinco horas que surcó la avenida San Juan / por la ribera izquierda, aquella / que fuérale asignada" (Samoilovich 12). También son habituales los trayectos que recorre la protagonista del poemario de Kamenszain: "teatros pizzerías música interrumpida de walkman / pasan de largo por el bajón de la marquesina / off off de los solos y solas / se apaga en la boca del subte" (Kamenszain 13). Desplazamientos ocasionales parecen ser los que realiza el sin trabajo en el texto de Mileo, mientras que el protagonista de Tedesco lleva a cabo un itinerario único en un momento singular de crisis.

En busca de una renovada exploración de sus potencialidades expresivas, el discurso poético contemporáneo suele asumir rasgos específicos de otros discursos, travistiéndose de los géneros más variados. Si todo viaje entendido como desplazamiento implica necesariamente una estructura narrativa (Rubio Martín 157), entonces podemos hablar de un cierto "relato de viaje" que subyace al diseño formal y semántico de los cuatro poemarios señalados $\mathrm{o}$, más bien, de un "efecto de relato de viaje" que produce su lectura. Es sabido que este último es un género problemático, cuyas lábiles fronteras apenas lo separan de la crónica, el diario o la guía. Sin embargo, Sofía Carrizo Rueda arribó a una definición que distingue al relato de viaje propiamente dicho de la gran marea de la literatura de viajes (Poética 29). De la definición de esta autora destacaremos algunas constantes morfológicas y pragmáticas que pueden ser rastreadas en los textos de Tedesco, Mileo, Kamenszain y Samoilovich. En primer lugar, la interrelación entre narración y descripción, 
que en los textos poéticos es esperable junto con los rasgos específicamente líricos que hacen a una "literatura de dicción" (Genette 32). Segundo, su naturaleza híbrida o bifronte que combina referentes del mundo real con dispositivos estéticos y ficcionales. Tercero, los índices o marcas textuales que atestiguan la estrecha relación de este tipo de discurso con el contexto sociocultural en el que fue producido. Cuarto, el importante rol que el libro de viajes asigna a los lectores y las lectoras, invitados a recorrer escrituras multiformes donde las referencias geográficas, históricas y culturales trazan una red autoral de pertenencias, identificaciones, denuncias o rechazos. Quinto, la capacidad del relato de viaje para poner de manifiesto conflictos, temores y expectativas del imaginario social.

Frente a la suma esquemática y tranquilizadora que ofrecen las guías turísticas, el relato de viaje ofrece una construcción problemática de un fragmento del mundo (Carrizo Rueda, "Estudio" 28-29). Su peculiar estructura acumulativa, independiente de cualquier tipo de límites y ordenamientos lógicos, permite almacenar todo un alud informativo en ocasión a las memorias de un itinerario, convirtiendo al relato en una especie de "almacén mnemónico" donde se incorpora "lo paradójico, lo sorpresivo, lo contradictorio, lo incierto" (Carrizo Rueda, "El viaje" 48-53).

En la mayoría de los libros de viaje ocurre que bajo las apariencias de la referencialidad, los enunciados pueden dar acceso a un segundo nivel de significación. La metonimia es una figura clave, pues se habla de una ciudad o de una región en general a partir de la descripción de uno de sus rincones o aspectos (Champeau 75-76). En los poemarios, la elección del personaje ya implica una serie metonímica que privilegia una determinada visión de la ciudad. Así resulta que la mujer divorciada asiste a eventos preparados para otros solteros maduros de clase media como ella y el desempleado recorre lugares funcionales a su condición, como un bar para leer el diario o el santuario de San Cayetano, patrono del trabajo. Del mismo modo, el personaje cartonero y el ahorrista burgués se vinculan con otros pares en espacios asociados a su ocupación y estatus. Ya hemos podido observar de qué modos la metáfora y la alegoría configuran el espesor semántico de las diferentes Buenos Aires representadas, constituyéndose en el instrumento privilegiado de la ideología. 


\section{DE LA DECONSTRUCCIÓN A LA EMPATÍA. CONCLUSIONES}

En un ensayo escrito en 1927, Virginia Woolf proponía el viaje en la ciudad como "la mayor de las aventuras" que permite escapar de uno/a mismo/a (Woolf $\mathrm{s} / \mathrm{p}$ ). Observar los espacios y las personas nos posibilita hurgar en la vida de los demás desatando la memoria y la imaginación propias. Con su street hunting la escritora inglesa se distanciaba del tradicional street sauntering, dando cabida a los aspectos inquietantes de una Londres crepuscular y moderna. Habiendo transcurrido ya ocho décadas de las pesquisas urbanas de Woolf y siete de las famosas apreciaciones parisinas de Benjamin, la ciudad actual guarda escaso margen para la flânerie. Como lo ha señalado Jean-Michel Maulpoix, en la poesía contemporánea no se producen encuentros en la calle porque el vagabundeo no apunta hacia un lugar físico; el poema traza en cambio una "tropología del decir" para probar el alcance de su voz y los límites de su comprensión (Maulpoix s/p).

Travestido de crónica o de relato de viajes, el discurso poético opera con estrategias de hipercodificación, tales como la transdiscursividad, el multiperspectivismo de la descripción, la polifonía enunciativa, la autoconfiguración testimonial o apócrifa del sujeto poético, la sincronicidad y la inestabilidad del sentido (Puppo, "Fragmentos" 135), todos factores que remiten a nuestra experiencia cotidiana en las grandes ciudades de principios del siglo XXI. El recorrido por cinco poemarios argentinos recientes nos ha enfrentado con diversas marcas textuales que traducen variables sociológicas de género, clase, edad, etnia, etc. Personajes de clase media, cartoneros, manifestantes, ciudadanos altruistas o enfadados, solteros y casados transitan por las calles de Buenos Aires con diferentes fines, ritmos y circuitos. Los textos líricos evocan su sed de afecto, sus angustias y preocupaciones apelando a la primera, segunda o tercera persona gramatical, desde la focalización en un personaje individual o colectivo. Según los poemarios analizados, la semiosfera porteña aparece saturada de signos dispares, pues la exigencia neurótica y el apuro de las clases medias conviven con la lentitud resignada de los pobres y marginales. La brecha insalvable entre pobres y ricos se cuestiona en un plano simbólico cuando la mujer burguesa se identifica como okupa y el desempleado se equipara a cualquier hombre sin amor. En estos "territorios del presente" (Ludmer 103) hay fronteras internas que separan los barrios y los trayectos, pero se evidencia la existencia concreta de un núcleo funcional conformado por la Capital Federal y los partidos provinciales que la rodean, lo que se designa como la Región Metropolitana de Buenos Aires. 
En las topografías poéticas de la crisis y la poscrisis llama la atención la ausencia de algunos habitantes y usuarios de la ciudad, como lo son las tribus urbanas de jóvenes, los ancianos, las parejas, los niños y los bebés. En el corpus seleccionado se tematizan los mayores problemas que hoy enfrentan los habitantes de la gran ciudad: el frío y el hambre que azotan a varios centenares de personas que duermen en la calle o en viviendas precarias, el trabajo infantil, el desempleo, las inundaciones, la decadencia del transporte público, el deterioro de la calidad ambiental producido por múltiples factores entre los que se cuentan la insuficiencia de pulmones verdes, la expulsión diaria de 5000 toneladas de basura y el nivel de ruidos que superan lo humanamente tolerable (AAVV s/p). También se alude al reciente auge de las industrias culturales y la actividad turística receptiva, a la inseguridad y la aparición de nuevos asentamientos. Tanto los grupos inmigratorios como la villa, actantes ineludibles en la configuración urbana, son mencionados en más de una oportunidad. Esta última aparece como referencia concreta en el texto de Samoilovich, cuando se menciona que los autobuses son "aligerados" al pasar la villa 31 (30). Por otra parte, en ninguno de los cinco textos analizados se explora un fenómeno creciente a partir de los años noventa, el auge de los countries o barrios privados en los municipios periféricos. Son estos espacios paradójicamente planteados como "islas no urbanas" (Muxí 50) los que más contribuyen a hacer de Buenos Aires una "ciudad difusa". Lo importante en este modelo de ciudad son las redes por donde circulan los medios de transporte, en tanto que el espacio público cobra su máximo sentido cuando vamos caminando (Rueda 78). No es casual, entonces, que los cinco poemarios analizados presenten visiones de la ciudad en tránsito, a partir de la mirada en movimiento de un personaje y/o la voz poética. De allí también el vínculo intertextual con la crónica y el relato de viaje, dos géneros especialmente aptos para la inclusión de situaciones y anécdotas diversas, el libre fluir de la memoria del narrador y el acopio de información heterogénea.

En el campo del imaginario hemos destacado las redes de metáforas que remiten a tópicos literarios tradicionales como lo son la caída de Troya (Samoilovich) y el descensus ad inferos y ad excrementum (Kamenszain, Tedesco). En estos versos, Buenos Aires surge bella, deforme e inclemente, al mismo tiempo la ciudad devoradora y devorada (Bellessi), el territorio insuficiente donde el agua lava las penas y ahoga a sus habitantes (Mileo). En dos ocasiones es convocado el matadero, un espacio paradigmático y fundacional de la literatura argentina. El poder simbólico de este recinto 
subsiste en el frigorífico que aún provee "carne argentroyana" a "la Ingalagrecia" (Samoilovich 47) o en el gesto del carnicero que "revive / el íntimo degüello" (Mileo 62).

Los textos seleccionados presentan escrituras difíciles, plagadas de inferencias y alusiones, que exigen lectoras y lectores altamente competentes y activos, involucrados con la situación política e histórica y conocedores de su mapa ideológico. En todos los poemarios se entretejen con ironía refranes, citas célebres y lugares comunes del habla porteña; entre ellos se destaca una pregunta que empezó a circular en los últimos años: “¿No crees que nos hemos vuelto más inteligentes y tolerantes, / Marforio, después del incendio / de nuestra amada Troya?" (Samoilovich 36). En las versiones paródicas de los arquetipos argentinos se revela el fondo oscuro del sentido común, donde se hacen presentes el racismo en todas sus manifestaciones, el uso demagógico del populismo de masas, la complicidad de los medios de comunicación con el gobierno de turno. La sensación del momento presente que se desprende de la mayor parte de los poemas es que todos somos "cadáveres... pasajeros, reciclables" (Samoilovich 42), porque la ciudad y el país ofrecen pocas promesas o garantías. Tal vez una referencia a la postguerra europea -el film Ladrones de bicicletas (1948), de Vittorio de Sica (Bellessi 145)- esté relacionada con la pregunta más importante formulada en plena crisis - $i$ "nos repondremos"? (Samoilovich 48)- y con el deseo de "que nunca / más nos suceda" (Bellessi 146).

En las distintas representaciones críticas del espacio urbano que ofrecen los textos poéticos hay indicios de una historia que confluyó para desembocar en la hecatombe. Se advierte una voluntad revisionista en las perspectivas históricas que desarrollan Tedesco y Samoilovich, una apuesta política en Bellessi, y un desencanto de la historia, la política y el Estado en Mileo. En este sentido, los poemarios seleccionados apuntan a la deconstrucción de varios mitos del pasado argentino, tendencia que coincide con un renovado interés en la sociedad por la novela histórica o la historiografía contada en clave de novela ${ }^{3}$. Con una sonrisa irónica los personajes recuerdan "los laureles que supimos conseguir", anunciados en el himno patrio, que no resultaron "eternos" (Mileo 38), así como el pasado glorioso de la nación agroganadera

3 Probablemente en este último registro se inscriba la saga de Felipe Pigna Los mitos de la historia argentina, volúmenes 1, 2, 3 y 4 (2004-2008), que desde su aparición constituye un gran éxito de ventas. 
y su tradición de derroche (Samoilovich 25, 26, 37). La nostalgia trae a la memoria la candidez del obrero peronista (Mileo 43) y con dolor se convocan los fantasmas que dejó la dictadura reciente (Tedesco). La sucesión de malos gobiernos y la corrupción que acecha en las instituciones alimentan la visión de una identidad pulverizada, que debe encontrar nuevos caminos colectivos mirando al futuro. Detrás de los avatares de los personajes y las diferentes voces que convergen en la ficción lírica, subsiste el rol del poeta como cronista -en el caso de Bellessi- así como la perspectiva del viajero o la viajera que avanza sin buscar respuestas taxativas. Estas voces y miradas nómades rescriben la ciudad en empatía con quienes sufren y callan, en un esfuerzo constante por interpelar el espacio físico y la realidad social.

¿Qué nos dejan en definitiva estos textos?, ¿qué nos invitan a esperar después del fin? Una conclusión a futuro surge del canto final de El carrito de Eneas. En un verso que en plena crisis económica mundial resulta profético, el sujeto poético nos recuerda que todas las cosas cambian, y así pues, como Troya, "el universo se expande y se enfría" (Samoilovich 55). Es esta una verdad física que se relaciona con el big bang y que la literatura evoca, más allá de los ciclos de la economía capitalista, como metáfora para repensar los espacios urbanos, las identidades subjetivas y los vínculos comunitarios.

\section{BIBLIOGRAFÍA}

AAVV. "Vida urbana: La baja de la calidad ambiental en Buenos Aires". Clarín, "La ciudad" (9/3/07): s/p. www.clarin.com

Alonso Lera, José Antonio. "Hacia un estatuto del elemento espacial en la novela". EPOS. XX-XXI (2005): 237-253.

Barrera, Trinidad. "Fernández Moreno y la ciudad de Buenos Aires". La ciudad imaginaria. Ed. Javier de Navascués. Madrid-Frankfurt: Iberoamericana-Vervuert, 2007. 69-88.

Bellessi, Diana. La rebelión del instante. Buenos Aires: Adriana Hidalgo, 2005.

Bernabé, Mónica. "La ciudad y sus metáforas en la narrativa de Edgardo Rodríguez Juliá". Actas del I Congreso Regional del Instituto Internacional de Literatura Iberoamericana. Rosario: 2005.

http://www.geocities.com/aularama/ponencias/abc/bernabe.htm

Prólogo. Idea crónica, literatura de no ficción iberoamericana. Comp. María Sonia Cristoff. Rosario: Beatriz Viterbo-Fundación TyPA, 2006. 7-24.

Carrizo Rueda, Sofía. Poética del relato de viajes. Kassel: Reichenberger, 1997.

"Estudio preliminar. Construcción y recepción de fragmentos de mundo". Escrituras del viaje. Construcción y recepción de fragmentos de mundo. Ed. Sofía Carrizo Rueda. Buenos Aires: Biblos, 2008. 9-33. 
"El viaje omnipresente. Su funcionalidad discursiva en los relatos culturales de la segunda modernidad". Letras. Número Monográfico El viaje y sus discursos. 57-58 (2008): 45-56.

Champeau, Geneviève. "Umbrales del relato y autorreferencia en los libros de viajes españoles contemporáneos". Letras. Número Monográfico El viaje y sus discursos. 57-58 (2008): 67-78.

Cristoff, María Sonia. “Cierto modo de contar el mundo". La Nación, ADN (17/1/09): 2022.

Depetris, Carolina. "La construcción de la realidad porteña en Misteriosa Buenos Aires". La ciudad imaginaria. Ed. Javier de Navascués. Madrid-Frankfurt: Iberoamericana-Vervuert, 2007. 135-146.

Foffani, Enrique. “Ausentes historias de amor”. La Nación. “Cultura”. (13/11/05): 4.

García Canclini, Néstor. Imaginarios urbanos. Buenos Aires: EUDEBA, 1997.

García Vega, Lorenzo. "El carrito de Eneas”. Miami Herald. “Artes y Letras”. (14/9/03): s/p. www.bajolaluna.com

Genette, Gérard. Fiction et diction. París: Seuil, 1991.

Kamenszain, Tamara. Solos y solas. Buenos Aires: Lumen, 2005.

Lefere, Robin. "Fervor de Buenos Aires, en contextos". La ciudad imaginaria. Ed. Javier de Navascués. Madrid-Frankfurt: Iberoamericana-Vervuert, 2007. 187-222.

Ludmer, Josefina. "Territorios del presente. En la Isla Urbana". Confines del Pensamiento. Buenos Aires: FCE. Diciembre, 2004: 103-110.

Maulpoix, Jean-Michel. Le poète perplexe. París: José Corti, 2002.

Mileo, Eduardo. Poemas del sin trabajo. Buenos Aires: En Danza, 2007.

Monteleone, Jorge. "Baldomero Fernández Moreno, poeta caminante". Cuadernos Hispanoamericanos. 429 (1986): 79-96. luna.com

"Cartoneros de la cultura". La Nación. "Cultura". (5/10/2003): s/p. www.bajola-

Muxí, Zaida. La arquitectura de la ciudad global. Barcelona: Editorial Gustavo Gili, 2004.

Neruda, Pablo. "Algunas reflexiones improvisadas sobre mis trabajos". Mapocho. Tomo II. Número 3 (1964): 180-182.

Prévôt Schapira, Marie-France. "América Latina: la ciudad fragmentada". Revista de Occidente. 230-231 (2000): 25-46.

Puppo, María Lucía. "Ficción, dicción, lírica y relato en Solos y solas (2005) de Tamara Kamenszain". Creación y proyección de los discursos narrativos. Actas del Cuarto Simposio Internacional del Centro de Estudios de Narratología. Eds. Daniel Altamiranda y Esther Smith. Buenos Aires: Editorial Dunken, 2008. 479-486.

"Fragmentos de un discurso apócrifo. El colonialismo revisitado en Estampas de ultramar (1986) de Aníbal Núñez". Escrituras del viaje. Construcción y recepción de fragmentos de mundo. Ed. Sofía Carrizo Rueda. Buenos Aires: Biblos, 2008. 119-138.

Rama, Ángel. La ciudad letrada. Hanover, New Hampshire: Ediciones del Norte, 1984. 
Raschella, Roberto. "Poemas en la ciudad de la ira". Revista Ñ (7/12/02): s/p. www.clarin. com.

Rubio Martín, María. "Nuevas cartografías del libro de viajes contemporáneo: la cultura especular”. Letras. Número Monográfico El viaje y sus discursos. 57-58 (2008): 149-162.

Rueda, Salvador. "La ciudad compacta y diversa frente a la conurbación difusa". AAVV. Ciudades para un futuro más sostenible. Madrid: Ministerio de Fomento, 1996. 69-80.

Saítta, Sylvia. "Ciudades revisitadas". Revista de Literaturas Modernas. 34 (2004): 135149.

Salomone, Alicia. Alfonsina Storni: mujeres, modernidad y literatura. Buenos Aires: Corregidor, 2006.

Samoilovich, Daniel. El carrito de Eneas. Buenos Aires: Bajo la luna, 2003.

Sarlo, Beatriz. Una modernidad periférica: Buenos Aires 1920 y 1930. Buenos Aires: Nueva Visión, 1988.

Savitch, H. V. "What is new about globalisation and what does it portend for cities?". International Social Science Journal. 172 (June 2002): 179-189.

Scarabelli, Sonia. "Reinvenciones de la voz". Todavía. 16 (abril 2007). <http://www.revistatodavia.com.ar/>

Spitta, Silvia. "Más allá de la ciudad letrada. Prefacio". Más allá de la ciudad letrada: crónicas y espacios urbanos. Eds. Boris Muñoz y Silvia Spitta. Pittsburg: Biblioteca de América, 2003. 7-23.

Tedesco, Luis. Aquel corazón descamisado. Buenos Aires: Grupo Editor Latinoamericano, 2002.

Woolf, Virginia. The Death of the Moth and Other Essays. Londres: Harvest, 1974. 